\title{
ABORDAGENS TERMODINÂMICAS: UMA ANÁLISE DAS LEIS E DOS PRINCIPAIS CONCEITOS EM LIVROS DIDÁTICOS
}

\author{
ENFOQUES TERMODINÁMICOS: ANÁLISIS DE LEYES Y PRINCIPALES \\ CONCEPTOS EN LIBROS DE TEXTO
}

THERMODYNAMIC APPROACHES: AN ANALYSIS OF LAWS AND MAIN CONCEPTS IN TEXTBOOKS

DOI: $10.22481 /$ rbba.v1i02.7800

Carlos Takiya

Universidade Estadual do Sudoeste da Bahia, Bahia, Brasil ORCID: https://orcid.org/0000-0002-2222-3198

Lattes: http://lattes.cnpq.br/6591206454491954

Endereço eletrônico: takiya@uesb.edu.br

Gabriel Fonseca Guimarães Universidade Estadual do Sudoeste da Bahia, Bahia, Brasil ORCID: https://orcid.org/0000-0002-8795-897X

Lattes: http://lattes.cnpq.br/6850946554302469 Endereço eletrônico: gabrielfonseca1415@gmail.com

Ian Lima Santana Universidade Estadual do Sudoeste da Bahia, Bahia, Brasil ORCID: https://orcid.org/0000-0002-2926-0792 Lattes: http://lattes.cnpq.br/6242705621816622 Endereço eletrônico: ianlimasantana@gmail.com

Luan Santos Lemos Universidade Estadual do Sudoeste da Bahia, Bahia, Brasil ORCID: https://orcid.org/0000-0003-2414-4191

Lattes: http://lattes.cnpq.br/9056768052086282 Endereço eletrônico: luan.santoslemos144@gmail.com 


\section{RESUMO}

O estudo e o entendimento da termodinâmica exige um criterioso processo de assimilação de leis e um conjunto bem estruturado de conceitos teóricos. Ao longo desse trabalho, vamos apresentar uma explanação dos principais conceitos envolvidos no estudo dessa ciência. Além disso, será exposto uma descrição de cada uma das quatro leis da termodinâmica firmando-se em conceitos fundamentais. Visamos, assim, uma análise das Leis e dos principais conceitos da Termodinâmica em livros didáticos com comentários críticos e descrições pertinentes a respeito de tais, apresentando ao longo do trabalho, os nossos próprios posicionamentos e conceitos a respeito delas, apresentando uma contextualização própria dessas Leis. Pôde-se constatar que pelos livros consultados, as quatro leis da Termodinâmica são fracamente abordadas de forma que seja possível entendê-las claramente, fazendo mero tratamento matemático das equações a elas relacionadas. Neste trabalho, buscou-se apresentar uma contextualização das quatro Leis da Termodinâmica, assim como a definição dos termos a elas associados, de forma clara, balizados, com base nas referências consultadas e apresentando um posicionamento conceitual a essas leis de forma que fosse possível dar um entendimento maior a elas.

Palavras - Chave: Termodinâmica; Leis; Princípios; Livros Didáticos.

\section{RESUMEN}

El estudio y la comprensión de la termodinámica requiere un cuidadoso proceso de asimilación de leyes y un conjunto conceptual teórico sólido y bien estructurado. A lo largo de este trabajo, presentamos una explicación de los principales conceptos aplicados a la Termodinámica. Además, también describimos cada una de las cuatro leyes termodinámicas, basándonos en sus conceptos centrales. Nuestro objetivo es analizar las cuatro leyes de la termodinámica y sus principales conceptos tal como lo presentan los libros de texto. Nuestro análisis intenta comentar críticamente y describir las definiciones anteriores, presentando nuestra posición y nuestros conceptos con respecto a las Leyes. Podríamos comprobar en los libros de texto que las cuatro Leyes se presentan de manera vaga, lo que dificulta su comprensión. Muchos de los autores solo muestran un enfoque matemático de las ecuaciones que abordan el tema. Además, los autores no parecen aclarar adecuadamente los conceptos físicos. En este trabajo, nos propusimos analizar la contextualización de cuatro Leyes de la Termodinámica, tal como las definen los conceptos relacionados con ella. Por lo tanto, intentamos comentarlo críticamente y luego nos posicionamos con el objetivo de definir las leyes y los conceptos de manera más adecuada.

Palabras clave: Termodinámica; Leyes; Principios; Libros de texto. 


\begin{abstract}
The study and understanding of Thermodynamics requires a careful assimilation process of laws and a solid well-structured theoretical conceptual set. Throughout of this work, we presents an explanation of the main concepts applied to Thermodynamics. Besides, we also describe each one of the four thermodynamic Laws, based on its core concepts. We aim to analyze the four Laws of Thermodynamics and its main concepts as textbooks present it. Our analysis try to critically comment and describe the definitions above, presenting our position and our concepts regards to the Laws. We could check in the textbooks the four Laws are presented in vague ways, making it difficult to understand them. Many of the authors only shows a mathematical approach of the equations that deal with the subject. In addition, the authors do not seem to clarify properly the physical concepts. In this work, we aimed to analyze the contextualization of four Thermodynamics Laws, as such as defined by the concepts related to it. Therefore, we tried to comment critically it and then made a stand with the goal of defining the laws and the concepts more properly.
\end{abstract}

Keywords: Thermodynamics; Laws; Principles; Textbooks.

\title{
1 INTRODUÇÃO
}

Consideramos que a termodinâmica é uma das principais áreas da Física, pois, conforme foi apresentado por Tipler (1976, p. 399): “A termodinâmica é o estudo dos processos de transferência de energia entre corpos macroscópicos e que envolvem a temperatura". Dessa forma, a termodinâmica engloba todo o campo de pesquisa relacionado ao estudo energético dos corpos, desde que possamos fazer essa análise pela perspectiva macroscópica.

Logo, em um mundo que depende cada vez mais da utilização de fontes de energia eficientes, conhecer as leis que garantem a conservação da energia, a sua conversão e principalmente que nem toda essa energia pode ser aproveitada de forma útil, é algo imprescindível. Todavia, sabemos que nem todas as grandezas físicas são apresentadas com a clareza necessária e no que tange a termodinâmica, essa dificuldade de encontrar definições precisas e completas fica ainda mais evidente (CORREIA; GUIMARÃES, 2020).

Entretanto, é notório que, para uma real compreensão do conteúdo, uma definição precisa é necessária. Pois, sem ela, o estudante pode ter uma má compreensão das grandezas fundamentais, o que pode levar a um entendimento deficiente dos fenômenos da natureza. Esse pensamento está de acordo com o que foi apresentado por Leite e Almeida (2001, p.459): 


\begin{abstract}
É incontroverso que a interpretação de um dado discurso escrito ou oral só pode ser correta tendo em consideração o contexto em que as expressões são usadas, o que é tanto mais importante quanto é certo que os mesmos vocábulos podem ser usados em diversos contextos com significados diferentes. Muitas palavras do vocabulário corrente são usadas em Física com um significado preciso e bem definido, e frequentemente os alunos, familiarizados com o sentido comum dessas palavras, não se apercebem do seu significado específico no contexto da Física. Por outro lado, os professores de Física do Ensino Superior têm como um dado adquirido o sentido específico desses termos e usam-nos naturalmente, sem se preocuparem em defini-lo ou clarificá-lo no contexto da disciplina. (...) O resultado é muitas vezes os estudantes pensarem que entenderam o que de facto não entenderam ou construírem, com base nos seus conhecimentos prévios e no sentido que atribuem às palavras, teorias incorretas, não científicas, ou apreensões incorretas de conceitos físicos. Grandezas definidas em ciência de um determinado modo podem, por isso, ser mal interpretadas no sentido de significarem qualquer coisa diferente.
\end{abstract}

Essa dificuldade de aprendizagem apresentada por estudantes, a exemplo da compreensão das definições das leis da termodinâmica e as grandezas relacionadas a ela (como a Temperatura, Energia Interna, Calor, Trabalho e Entropia) contribui de forma negativa no labor deles quando se tornarem profissionais, devido ao seu entendimento intuitivo incipiente.

Logo, este artigo busca apresentar as quatro Leis da Termodinâmica, assim como a definição dos termos a ela associados, de forma clara, balizados pelo silogismo aristotélico.

\title{
2. MÉTODOS DE PESQUISA
}

A Termodinâmica é um dos principais campos de estudo da Física, isso é devido principalmente a sua vasta aplicação, e pelo fato das suas leis serem baseadas em observações experimentais. Todavia, mesmo com sua natureza experimental, um entendimento teórico das suas leis, baseando nas suas definições, e utilizando princípios lógicos, se faz necessário para uma maior compreensão desse campo, tanto por parte dos estudantes, quanto dos pesquisadores.

Dessa forma, fizemos uma análise das definições apresentadas por alguns autores, levando em conta o contexto histórico e apresentando a nossa interpretação a respeito do assunto, quando consideramos pertinente. Por esse motivo utilizamos o silogismo aristotélico para balizar nossa metodologia de pesquisa, uma vez que "Aristóteles não apenas se preocupa com os problemas das ciências teóricas particulares, mas também com os problemas epistemológicos da pesquisa científica” (NAKAZA; LINHARES, 2017, p. 2). 
Devemos ressaltar que para Aristóteles, a própria demonstração era o silogismo científico. Isso fica evidente em um trecho atribuído a ele (ARISTÓTELES, 350 a. C., 71b 16) e traduzido por Angioni (2004, p. 15): “por ‘demonstração’ entendo silogismo científico; e por ‘científico' entendo aquele segundo o qual conhecemos cientificamente por possuí-lo.”. Logo, se estamos à procura de uma definição e demonstrações verdadeiras, precisamos que partam de premissas que sejam verdadeiras, conforme Aristóteles (350 a. C., 71b 19):

Assim, se conhecer cientificamente é como propusemos, é necessário que o conhecimento demonstrativo provenha de itens verdadeiros, primeiros, imediatos, mais cognoscíveis que a conclusão, anteriores a ela e que sejam causas dela. Pois é deste modo que os princípios serão de fato apropriados ao que se prova. É possível haver silogismo mesmo sem tais itens, mas não é possível haver demonstração. Pois, tal silogismo não poderia propiciar conhecimento científico. (apud ANGIONI, 2004, p. 15).

Sendo assim, inspirados pelo silogismo aristotélico, abordamos cada uma das quatro leis da Termodinâmica.

\section{LEI ZERO DA TERMODINÂMICA}

A medição da temperatura é uma técnica que foi se desenvolvendo com o tempo, até a época de Galileu, considerado o inventor do primeiro termômetro, não existiam métodos para se medir com uma "boa" precisão o valor da temperatura. Apesar de usarmos em nosso cotidiano termos qualitativos para descrever a temperatura como "quente" ou "frio", não podemos atribuir valores numéricos para caracterizar a temperatura com base apenas em qualidades.

Nossos corpos tem facilidade em perceber a diferença de temperatura, não a temperatura real. Um exemplo cotidiano seria encher três baldes com água, o primeiro balde com água a 290 Kelvins, o segundo com água a 320 kelvins e um terceiro a temperatura ambiente, aproximadamente 300 kelvins. Se colocássemos a mão esquerda no primeiro balde e a direita no segundo, quando colocássemos as duas no terceiro balde a água dele pareceria quente para a mão esquerda, porém, estaria fria para a mão direita.

Dessa forma, fica claro que precisamos de meios mais efetivos para fazer uma medição e chegar a valores precisos. Todavia, sabemos que não podemos medir a temperatura diretamente, pois, precisaríamos saber a energia cinética de cada molécula, o que é atualmente impossível. Então, para chegar a um valor quantitativo para a temperatura, ao invés de fazer 
considerações microscópicas, fazemos considerações macroscópicas ao nos basearmos em propriedades dos materiais que mudam de acordo com a temperatura. E com base nessa ideia foram criados os primeiros termômetros, por exemplo, temos o conhecido termômetro de mercúrio, que tem como base a expansão do mercúrio com o aumento da temperatura.

Muitos dos materiais didáticos pesquisados, na área de termodinâmica, associam temperatura ao calor, o que é um equívoco. Pois, conforme foi apresentado por Correia (2017): “calor é a energia em estado de transferência entre dois sistemas devido à diferença de temperatura entre esses dois sistemas". O que, a priori, nada tem a ver com temperatura, que consideramos que foi bem definida da seguinte forma por Costa (1971, p. 16):

A temperatura, de acordo com considerações puramente termodinâmicas, é,
como qualquer outra característica de estado, determinada por meio de
observações experimentais dos corpos como um todo, enquanto que de acordo
com a Teoria Cinética, pode a mesma ser avaliada de acordo com a energia
cinética média das moléculas. Ou seja, para uma real compreensão da temperatura, precisamos abordar também conceitos microscópicos, que são do escopo da Mecânica Estatística. Todavia, Costa (1971, p. 16). ainda faz a seguinte afirmação:

A temperatura é o conceito físico que nos permite medir o estado térmico de um sistema, estabelecendo a sua maior ou menor capacidade de transmitir calor, ou ainda, de acordo com a teoria cinética, a energia média de suas moléculas.

Apesar de considerarmos que o texto acima possui uma das melhores definições encontradas em nossa pesquisa, ele possui erros conceituais. Pois, não é possível "transmitir calor”, pois calor é uma Função de Transformação, não uma propriedade do sistema. E mesmo se trocássemos o termo por energia térmica, ainda não estaria correto, porque a maior ou menor capacidade de transmitir energia térmica não está diretamente ligado a temperatura do sistema e sim a diferença de temperatura entre dois sistemas.

Dessa forma, por exemplo, ao isolarmos dois corpos com temperaturas diferentes em um sistema fechado, ocorrerá inevitavelmente a transferência de energia térmica do corpo com maior temperatura para aquele com menor, e essa transferência se mantém até que ambos os corpos tenham atingido a mesma temperatura entre si ou atinjam o chamado equilíbrio térmico.

Então, o conceito por traz da Lei Zero da Termodinâmica envolve justamente essa ideia de equilíbrio térmico. Se queremos definir ou entender a lei precisamos, em primeiro lugar, 
compreender o que significa equilíbrio térmico. Como o conceito de equilíbrio térmico é muito importante em termodinâmica vamos apresentar uma definição para ele, porque esse conceito seria, ao nosso ver, uma ideia primitiva em relação a lei zero da termodinâmica sabendo que, na definição da lei zero usamos o termo equilíbrio térmico, em que, dizemos que dois sistemas estão em equilíbrio térmico entre si, ao colocarmos eles em contato, não existindo transferência de energia térmica e ao compararmos a temperatura de ambos os sistemas com um terceiro corpo não é vista nenhuma diferença de temperatura de um sistema para o outro.

É um princípio básico da natureza admitir que quando dois corpos com temperaturas diferentes são mantidos nas proximidades um do outro, eles tendem a chegar a uma mesma temperatura após um certo intervalo de tempo.

Agora podemos apresentar um enunciado que declare o que diz a lei zero da termodinâmica e dessa forma, tem-se o seguinte: Se dois corpos A e B estão separadamente em equilíbrio térmico com um terceiro corpo $\mathrm{C}$, então $\mathrm{A}$ e B estão em equilíbrio térmico entre si. Conforme cita Çengel e Boles (2007, p.14):

A Lei Zero da Termodinâmica declara que se dois corpos estão em equilíbrio térmico com um terceiro corpo, eles também estão em equilíbrio térmico entre si. [...] Entretanto, tal fato não pode ser concluído a partir das outras leis da termodinâmica, e serve como base para a validade da medição da temperatura. Ao substituir o terceiro corpo por um termômetro, a Lei Zero pode ser reescrita como dois corpos estão em equilíbrio térmico se ambos tiverem a mesma leitura de temperatura, mesmo que não estejam em contato. (Grifo dos autores).

Temos, então, que a Lei Zero não define temperatura. Mas, ao estabelecer uma certa propriedade transitiva entre os corpos, ela nos fornece um meio de medir a temperatura dos corpos observando apenas as propriedades macroscópicas. Surpreendentemente a lei zero foi a última das leis termodinâmicas a ser formulada e reconhecida como um princípio fundamental, pois ela não pode ser deduzida a partir de nenhumas das outras leis já conhecidas à época de sua formulação. Isso se deu, na verdade, por haver uma necessidade, a priori, de um conceito introdutório às leis da termodinâmica.

\section{PRIMEIRA LEI DA TERMODINÂMICA}

Em meados do século XIX os cientistas buscavam quantificar as relações entre as diferentes formas de energia. Buscou-se, então, estabelecer uma equivalência entre as várias 
manifestações de energia. E isso fundamentou a demonstração do princípio de conservação, e o modelo subjacente decorrente desse esforço passou a ser chamado de equivalente mecânico do calor.

Em um site da internet encontramos uma nota de aula sobre Conceitos básicos e postulados da Termodinâmica, obtivemos a seguinte informação sobre a pesquisa feita por Joule para estabelecer tal equivalência:

As primeiras medidas de Joule sobre equivalência entre energia e calor apresentaram uma grande variabilidade e não eram muito confiáveis, mas ele continuou repetindo seu experimento, cada vez com mais precisão, e, em 1850, pôde obter um valor muito próximo do atual: $1 \mathrm{cal}=4,186 \mathrm{~J}$. É em homenagem a Joule que se deu o nome da unidade em que se mede energia. ${ }^{i}$

Ao se entender que existe uma estreita relação entre trabalho mecânico e calor nos processos termodinâmicos chegamos a ter a confirmação de uma ideia, que já tinha sido sugerida muito tempo antes de uma forma bem mais simples por outros estudiosos como Gottfried Wilhelm Leibniz, o chamado Princípio de Conservação da Energia. E entendemos que a Primeira Lei da Termodinâmica nada mais é do que uma reafirmação desse princípio.

Todavia, é importante frisar que James Prescott Joule foi o primeiro cientista que chegou a essa conclusão baseada em seus experimentos. A partir desses experimentos, ele pôde concluir que a energia não pode ser criada ou destruída, ela pode ser apenas transformada de uma forma em outra.

Mas, de todo modo, essa ideia já não era tão nova no desenvolvimento da ciência da época. Pois algumas décadas antes, no século XVIII, o químico francês Antoine Lavoisier postulou um importante princípio muito usado em Química e Física conhecido como Lei de Conservação das Massas ou Lei de Lavoisier, que de todo modo, afirma a conservação de matéria na natureza.

A semelhança entre esses dois princípios não é uma simples coincidência, pois, conforme foi mostrado por Einstein na sua equação mais famosa, existe uma equivalência entre massa e energia. Ou, conforme foi apresentado por Costa: "massa e energia são, portanto, formas diversas de um mesmo fenômeno". (COSTA, 1971, p. 16).

De posse do entendimento de como foi formulada a lei de conservação da energia, acreditamos que ainda seja fundamental para o leitor ter uma ideia do que são Calor e Trabalho para ter uma real compreensão da Primeira Lei da Termodinâmica. 
Como já foi dito, apesar do termo Calor ser muito utilizado no cotidiano, ele é empregado muitas vezes de forma incorreta. O termo Calor é muitas vezes tratado como propriedade de um sistema, enquanto, na verdade, ele é uma transformação. Em muitos dos materiais analisados foram encontrados termos como: "transferência de calor", "fluxo de calor", o que mostra que se faz necessário apresentar uma definição concisa e precisa do que é o Calor, para que não ocorram erros de termologia desse tipo. Conforme foi apresentado por Correia e Magalhães (2009, p.737):

Observa-se que o calor é normalmente definido como a energia que é transferida de um corpo para outro devido à diferença de temperatura entre os corpos. Essa transferência cessa quando é estabelecido o equilíbrio térmico. Entretanto, após o equilíbrio térmico, essa quantidade de energia que foi transferida, que é usualmente denominada de calor, pode não ser constatada, pois, no corpo, essa energia pode sofrer uma transformação. Logo, podem ocorrer situações em que essa quantidade de energia, em forma de calor, pode não ser obtida na sua integralidade em função apenas da diferença de temperatura que o corpo sofreu ao trocar energia térmica. Entendemos que a energia em forma de calor só deve ser definida durante o processo de transferência. E neste sentido é que entendemos que o verbo "transferir" não deve ser usado no tempo passado. Entendemos também que a energia atribuída ao calor deve ser renomeada para energia térmica, a partir do momento em que se encontra no lugar de origem ou destino, principalmente quando não se analisou a denominação que essa energia irá assumir. Entretanto, pode ser garantido que a sua origem é térmica, quando tal transferência estiver condicionada a uma diferença de temperatura.

Usando a seguinte definição: temos, então, que calor é a energia em transferência de um corpo para outro devido unicamente a diferença de temperatura. Notemos ainda o uso do termo “em transferência” implica que a energia que já foi transferida não é mais calor. Ou seja, essa energia que transita de um corpo para outro devido unicamente a diferença de temperatura só é calor no momento em que ela é transferida.

Outro conceito fundamental para entendermos a Primeira Lei da Termodinâmica é o conceito de trabalho. Assim como o Calor, Trabalho também é uma grandeza de transformação. Apesar disso, também é tratado muitas vezes equivocadamente como propriedade de um sistema. O trabalho foi apresentado da seguinte forma por Correia (2011, p.213):

Consideramos dois sistemas (A e B) o trabalho de uma força que o sistema A exerce sobre o sistema $B$ representa a transferência de energia de um sistema para o outro. O sistema A perdeu energia, por meio do trabalho realizado pela força, representado matematicamente como o produto da força que o sistema A exerce sobre o sistema B pelo deslocamento do sistema B; enquanto que o 
sistema B ganhou energia, cujo módulo dessa energia adquirida é dada pela expressão matemática da variação da energia cinética do sistema B.

Agora, com a seguinte definição: o Trabalho é toda energia em transferência de um corpo para outro desde que essa energia não seja em decorrência unicamente da diferença de temperatura entre os corpos. Ou seja, assim como o Calor, só faz sentido falar de trabalho no momento da transferência.

Falta ainda definir uma grandeza fundamental para o entendimento da Primeira Lei da Termodinâmica, que é a Energia Interna. Erroneamente muitos matérias analisados afirmam que a Energia Interna é definida pela Primeira Lei da Termodinâmica, enquanto, que, na verdade, nessa é definida a variação da energia interna.

A Energia Interna de um sistema, é toda energia que um sistema possui devido à sua constituição interna e foi assim definida por Correia e Oliveira (2019, p.331):

Da Primeira Lei da Termodinâmica, já é sabido que existe uma Função de Estado $U$ associada ao sistema, cuja variação é dada pelo saldo das trocas de energia desse sistema ao interagir com outro sistema. Essa função é denominada por Energia Interna, que representa toda energia de um Sistema Termodinâmico devido à sua constituição interna.

Agora, compreendendo o significado de todas as grandezas presentes na Primeira Lei da Termodinâmica, podemos finalmente defini-la, em que, as variações de energia que um sistema termodinâmico pode sofrer dependem em unidade e medida de quantidades intrínsecas do próprio sistema ou de seu exterior, isto é, o trabalho e o Calor. Portanto, a energia interna de um sistema varia dependendo tão somente da energia fornecida na forma de Calor e do trabalho realizado.

Esse enunciado pode ser expresso de forma matemática, descrevendo como ocorre a variação da energia interna $\Delta U$ de um sistema durante uma mudança de um estado arbitrário para outro, por:

$$
\Delta U=Q+W
$$

De todo modo, podemos aqui considerar a formulação da Primeira Lei da Termodinâmica feita pelo físico alemão Rudolf Clausius. A formulação que foi feita por Clausius em um artigo que ele publicou em 1850, intitulado "Da força motriz do calor e das leis sobre o calor que daí se podem deduzir", foi encontrada em um site da internet, da seguinte forma: "quando um sistema sofre uma transformação, a soma algébrica das diversas variações 
de energia, do fluxo de calor, do trabalho efetuado, etc., é independente do mecanismo dessa transformação. Ela só depende do estado inicial e final do sistema’’ii.

Como já foi dito, não existe fluxo de calor. Mas, como historicamente acreditava-se que calor era uma propriedade de um corpo, em fontes mais antigas é muito comum ler-se tal termologia. No geral existem várias formas de enunciar as Leis da Termodinâmica, a única exceção é a Lei Zero que tem uma formulação fixa, não sendo possível mudar muito aquele enunciado apresentado nos tópicos acima. Já no caso das outras leis é possível se encontrar nos livros-texto diversas variações das definições das leis. Então, neste trabalho iremos expor sempre mais de uma definição para essas leis, buscando fazer uma análise pertinente aos conceitos envolvidos e estabelecer e definir os possíveis conceitos mais cabíveis a tais definições.

\section{SEGUNDA LEI DA TERMODINÂMICA}

As Leis da Termodinâmica e seus conceitos subjacentes surgiram principalmente no desenrolar da Primeira para a Segunda Revolução Industrial, baseado no esforço de vários cientistas na busca pelo entendimento por traz do funcionamento das máquinas térmicas. Uma busca incessante atrás de um princípio fundamental que permitiria ao ser humano construir uma máquina térmica ideal, também chamada de motor contínuo, que em tese teria um rendimento perfeito, de cem por cento, ou seja, sem perdas energéticas.

Hoje sabemos que tal máquina é impossível de ser construída, pois em um sistema termodinâmico como é o caso de uma máquina térmica (consideremos aqui um sistema aberto) que consiste de uma fonte quente (com temperatura $T_{1}$ ) e uma fonte fria (com temperatura $T_{2}$ ), onde $T_{1}>T_{2}$, em que uma parcela da quantidade de energia térmica gerada pelo processo é transformado efetivamente em trabalho mecânico útil e a outra parcela si dissipa na fonte fria.

Entretanto, falando de forma bem simples e intuitiva, para ser ideal, a máquina deveria transformar toda essa energia térmica em trabalho mecânico, o que, como já foi dito, não é possível. Existe um limite teórico quando falamos do rendimento de uma máquina e tudo isso foi estudado pelo físico e engenheiro francês Nicolas Léonard Sadi Carnot, um brilhante cientista que de acordo com alguns livros é tido como o fundador da Ciência Termodinâmica e dele partiu uma das leis dessa.

A Segunda Lei da Termodinâmica pode ser usada como justificativa para essa limitação das máquinas térmicas, descrita anteriormente, e um dos primeiros cientistas que observou isso

Revista RBBA $\mid$ Revista Binacional Brasil Argentina 
foi Carnot. Ele não só descreveu como se dava essa limitação das máquinas térmicas, mas também determinou o porquê isso acontece, e para explicar esse porquê, ele teve que elaborar um novo princípio termodinâmico. Então, primeiramente vamos tentar definir o significado de entropia no contexto da Termodinâmica, sabendo que a entropia de um sistema é um conceito que oferece a base para a Segunda Lei.

No estudo da Termodinâmica podemos distinguir dois tipos diferentes de processos; os processos reversíveis e os irreversíveis. Se um processo é executado, ele obviamente irá causar uma mudança no estado de um sistema termodinâmico, o que acarreta modificações nas variáveis de estado do sistema, no entanto, se for possível alterar o sistema novamente fazendoo retornar as suas condições iniciais, então chamamos esse último processo realizado de reversível. Caso não seja possível realizar esse processo inverso, então, chamamos o primeiro de irreversível.

Conforme já foi dito, é impossível converter toda a energia na forma de calor em energia na forma de trabalho em um processo reversível. Entretanto, já afirmamos anteriormente que existe uma Lei de Conservação da Energia, então, tal energia não pode simplesmente desaparecer. O que ocorre é que parte da energia é transformada em um tipo de energia não útil, ou seja, que não pode ser utilizada para realizar trabalho, tal energia é denominada entropia.

A Entropia foi assim apresentada por Máximo e Alvarenga (1977, p.650):

Suponha que uma certa massa de água quente seja misturada com uma porção de água fria. Como sabemos, este sistema, resultante da mistura, termina por alcançar uma mistura de equilíbrio, que tem o mesmo valor em qualquer ponto do sistema. (...) Evidentemente, antes de ser efetuada a mistura, teria sido possível fazer uma máquina térmica operar usando as massas de água mencionadas como fonte quente e fria dessa máquina. Isto é, a energia que foi transferida da massa de água quente para a fria poderia ter sido utilizada para realizar trabalho (energia útil). (...) Entretanto, após a mistura, sendo atingida a uniformidade de temperatura do sistema, embora não tenha havido desaparecimento de energia, não é mais possível convertê-la em trabalho. Vemos então que uma parte da energia tornou-se indisponível, em outras palavras, não podemos usá-la de forma útil. Para aquela parte de energia continuasse disponível para a realização de trabalho, seria necessário que o sistema (suposto isolado) voltasse espontaneamente às condições iniciais, isto é, a mistura se separasse nas duas porções quente e fria primitivas. De nossa experiência diária sabemos que isto nunca ocorre, ou seja, o processo que levou à homogeneização da temperatura é irreversível.

Outra maneira de analisar este processo consiste em observar que o sistema inicialmente encontrava-se em condição mais organizada, isto é, de maior ordem, com as moléculas de maior energia cinética média (água quente) separadas das moléculas de menor energia cinética (água fria). Depois que 
ocorre a mistura, o sistema torna-se mais desordenado, com as moléculas distribuídas aleatoriamente, havendo uma uniformidade da temperatura.

Ou seja, apesar do termo ser muito corriqueiro no dia a dia, não se sabe com precisão o que é Entropia, ela apenas é relacionada a outras grandezas. Outra questão vinculada a essa grandeza é que ela é relacionada a probabilidade e a partículas, então, talvez fosse melhor trabalhada em um estudo de Mecânica Estática ou Mecânica Quântica.

Correia e José (2013, p. 209) apresenta essa mesma grandeza dizendo que "em suma a entropia está relacionada à medida da quantidade de energia que não foi convertida em trabalho mecânico, que é avaliada pela sua variação”. Agora, com o entendimento básico sobre entropia, podemos enfim apresentar uma das versões da Segunda Lei da Termodinâmica, elaborado em 1824 por Sadi Carnot, que buscamos em um site da internet enunciado da seguinte forma:

Para haver conversão contínua de calor em trabalho, um sistema deve realizar ciclos entre fontes quentes e frias, continuamente. Em cada ciclo, é retirada uma certa quantidade de calor da fonte quente (energia útil), que é parcialmente convertida em trabalho, sendo o restante rejeitado para a fonte fria (energia dissipada) ${ }^{\mathrm{iii}}$.

Sabemos que é impossível retirar calor, pois, calor não é uma propriedade de um corpo. Logo, o termo que se encaixaria melhor na frase acima seria: é retirada energia térmica, na forma de calor, da fonte quente. Temos ainda que, o termo Energia Dissipada apresentado no segundo princípio esteja relacionada a entropia anteriormente comentada.

Um outro físico que teve grandes contribuições para o estudo da Termodinâmica foi Rudolf Clausius, como já mencionado anteriormente, em que ele desenvolveu conceitos importantes para o melhoramento do entendimento dos sistemas termodinâmicos, como o de entropia, que será uma ideia importante para construirmos o nosso enunciado da Segunda Lei, mais adiante.

Até agora apresentamos apenas uma das aplicações da Segunda Lei da Termodinâmica que foi a determinação dos limites teóricos das máquinas térmicas, bem como, alguns dos conceitos relacionados a ela e algumas de suas formulações. Mas, além disso, esse princípio pode ser usado para indicar a direção de um processo termodinâmico, algo que não é possível de se fazer usando apenas o princípio de conservação. Para deixar mais claro essa ideia de direção de um processo recorremos a um exemplo que é corriqueiramente usado pelos livros didáticos. 

PRINCIPAIS CONCEITOS EM LIVROS DIDÁTICOS

Consideremos uma xícara de café quente colocada em uma sala fria. É de se esperar que com o passar do tempo esse café irá esfriar, e isso obviamente obedece ao princípio de conservação da energia, pois toda energia perdida pelo café é transferida ao ambiente. Mas, e se pensássemos no processo inverso (em outras palavras mudando a direção do processo), ou seja, esperar que depois que a xícara de café e o ambiente adquiriram o equilíbrio térmico (Lei Zero), o sistema (xícara de café e a sala) possa voltar ao seu estado inicial. E não deixa de ser natural em nossa vivência cotidiana admitir que seria claramente impossível, que esse último processo (denominado inverso) venha a ocorrer na natureza.

Esse exemplo, então, serviu para esclarecer a ideia de direção de um processo e, como já definimos os tipos de processos termodinâmicos, se fosse possível seguir a direção de ida e volta num determinado processo, então ele seria chamado de reversível. Por isso, dizemos que esse processo reversível é apenas uma idealização conveniente para alguns estudos, sendo que todos os processos reais que ocorrem na natureza são irreversíveis.

Essa energia que não pode ser obtida de volta pode ficar mais clara quando tratamos dos Potenciais Termodinâmicos, como o Potencial de Helmholtz e o Potencial de Gibbs. Pois, em suma, eles nos dizem que nem toda a energia que um sistema possui pode ser recuperada no momento de sua "destruição" (lembramos, aqui, que o termo "destruição" neste contexto se refere a uma transformação).

Fizemos aqui uma breve explanação de conceitos subjacentes à Segunda Lei, mas de todo modo apresentamos apenas o enunciado dado para a lei por Carnot, contudo esse não é o único. Existem vários enunciados para esse princípio, porém, dentre todos há dois enunciados clássicos quando falamos da Segunda Lei, que são o enunciado de Kelvin-Planck e o de Clausius. E de acordo o enunciado de Kelvin-Planck, visto em (ÇENGEL; BOLES, 2007, p. 230): “é impossível para qualquer dispositivo que opera em um ciclo receber calor de um único reservatório e produzir uma quantidade líquida de trabalho".

Novamente, o dispositivo não recebe calor, nem o reservatório possui calor. O primeiro recebe energia térmica na forma de calor e o segundo fornece energia térmica na forma de calor. Entretanto, fazendo as devidas correções, temos que em essência ele reafirma o que já dissemos, que uma máquina térmica precisa de duas fontes, uma a alta temperatura e a outra a baixa temperatura, para que a máquina se mantenha em operação e não existe um dispositivo térmico que opere com cem por cento de eficiência. 
Já o enunciado de Clausius diz que: "é impossível construir um dispositivo que funcione em um ciclo e não produza qualquer outro efeito que não seja a transferência de calor de um corpo com temperatura mais baixa para um corpo com temperatura mais alta" (ÇENGEL; BOLES, 2007, p. 234).

Novamente, temos que o calor foi tratado como propriedade de um corpo. O que ocorre é uma transferência de energia térmica na forma de calor devida unicamente a diferença de temperatura entre os corpos.

Então ambos os enunciados expressam a Segunda Lei. Claro que as declarações são um tanto diferentes, e dessa forma suas consequências também se diferem de modo que enquanto o de Kelvin-Planck se refere as máquinas térmicas, esse enunciado de Clausius se refere as "bombas" de calor e aos refrigeradores, ele garante que é possível construir tais dispositivos e eles operam de acordo com essa lei.

Agora apresentamos um enunciado independente dos que já foram apresentados até anteriormente e que envolva o conceito de entropia, em que se segue: em qualquer sistema termodinâmico isolado, sofrendo um processo irreversível, o grau de entropia tenderá a um aumento crescente no decorrer do tempo. Depois que o sistema atingir seu máximo grau de entropia toda a energia do sistema se encontrará indisponível para a realização de trabalho. $\mathrm{O}$ que por sua vez, constitui um conceito que permite um bom entendimento da entropia de um sistema.

\section{TERCEIRA LEI DA TERMODINÂMICA}

Como sabemos, o conceito de temperatura é fundamental dentro da Termodinâmica. A temperatura é em si uma variável de estado que descreve em conjunto com outras variáveis um sistema seja ele macroscópico ou não, mas em decorrência da Lei Zero, a temperatura só pode ser definida quando há equilíbrio térmico. A ideia de temperatura está intimamente relacionada com a Lei Zero da Termodinâmica, sem a qual não teríamos a base para definir o princípio e, é claro, não deixa de ter sua importância quando consideramos a primeira e segunda leis, e agora que estamos falando da Terceira Lei da Termodinâmica, esse conceito será usado de forma recorrente porque, assim como foi para a Lei Zero, precisaremos do conceito de temperatura para definir o enunciado dessa lei.

Porém, antes de apresentarmos qualquer enunciado para essa lei, vejamos mais algumas informações sobre a ideia de temperatura. É uma noção comum que temos hoje na ciência de Revista RBBA Revista Binacional Brasil Argentina 
que a temperatura representa o grau de agitação de partículas (átomos ou moléculas) que compõem um dado sistema, um exemplo bastante usado é o chamado gás ideal. Se aumentarmos a energia interna de um gás oferecendo (não necessariamente) energia térmica, na forma de calor, a ele teremos como consequência um aumento gradual da temperatura, então, neste exemplo, a temperatura está associada ao aumento da energia interna, em que esta poderia ser encarada como o somatório das energias cinéticas das partículas acrescido das energias potenciais decorrentes das interações entre as partículas do sistema.

O que pretendíamos apresentar nesse último trecho foi que um aumento da temperatura em função do calor, por exemplo, provoca um aumento na velocidade de agitação dos átomos ou moléculas do sistema. Então, aqui surgem duas perguntas interessantes; se a temperatura está relacionada com a agitação das partículas dos sistemas termodinâmicos em nível microscópico, quando deveríamos esperar que essa agitação fosse mínima? Seria possível que o grau de agitação viesse a ser indubitavelmente zero? A Terceira Lei da Termodinâmica surge, dentre outras coisas, com o objetivo de esclarecer questões como essas, no contexto em que os cientistas buscavam saber se existia de fato uma temperatura mínima admitida pela natureza, o chamado zero absoluto.

Agora, com base nessas ideias descritas e no conceito de entropia, apresentaremos uma possível interpretação do enunciado da Terceira Lei, com base no enunciado de Walther Nernst. Dele, podemos concluir que quando a temperatura em um sistema termodinâmico fechado se aproxima do zero absoluto, a entropia do sistema tende a um valor constante. Em palavras mais simples, o que isso quer dizer é que à medida que a temperatura $T$ se aproxima do zero absoluto $(T \rightarrow 0 K)$ o grau de agitação das partículas tende a se estabilizar. Dessa forma, a variação da entropia tende a zero.

Pois, se tratarmos a entropia como uma medida do grau de desordem de um sistema e, se as partículas desse sistema estão em repouso no intervalo do momento A para o momento B, não ouve aumento da desordem nesse intervalo de tempo. Logo, toda a energia que podia ser convertida em trabalho no momento A ainda pode ser convertida em trabalho no momento B. Matematicamente esse enunciado pode ser descrito pela equação:

$$
\lim _{T \rightarrow 0} \Delta S=0
$$

Um outro enunciado que foi elaborado para descrever a Terceira Lei da Termodinâmica foi dado por Max Planck. Por esse enunciado, temos que a variação da entropia, em um sistema Revista RBBA Revista Binacional Brasil Argentina 
termodinâmico, só se anula quando a temperatura "atinge" o zero absoluto. Uma das consequências mais importantes da Terceira Lei é que, quando a temperatura tende ao zero absoluto uma máquina pode ter um rendimento próximo dos $100 \%$, ou seja, a energia térmica pode ser transformada integralmente em trabalho, o que por sua vez é algo impossível/intangível em um processo cíclico na Termodinâmica.

\section{EQUAÇÕES ENVOLVIDAS NOS CONCEITOS DAS LEIS DA TERMODINÂMICA}

\subsection{Primeira Lei e a Variação da Energia Interna}

Depois de termos discutido em tópicos anteriores, os conceitos e as definições básicas da Termodinâmica por trás de seus princípios e de suas leis fundamentais, partiremos agora em busca de justificativas matemáticas mais convincentes para as descrições quantitativas (fórmulas matemáticas em si) das Leis da Termodinâmica e para isso faz-se necessário algumas novas definições que serão importantes no estudo que faremos a seguir.

Definição 1: Calor e Trabalho são mecanismos de transferência de energia entre um sistema e sua vizinhança. Assim, essa condição deve ser levada em consideração em todas as considerações matemáticas.

Definição 2: Funções de trajetória, também chamadas de função de linha (é o caso do Calor e do Trabalho) é quando o valor atribuído a função depende do caminho (trajetória) percorrido pelo sistema, dizemos que as funções de linha são as propriedades que estão relacionadas diretamente com uma determinada transformação sofrida pelo sistema.

Em um diagrama sua representação é de uma linha unindo os dois estados entre os quais a transformação está ocorrendo. Assim, não seria apropriado analisar essa função por cada ponto da curva individualmente, e sim analisar a curva entre dois pontos dados. Em termos matemáticos, dizemos que essas funções possuem diferenciais inexatas, designadas pelo símbolo $\delta$.

Definição 3: Toda e qualquer propriedade termodinâmica é designada como uma função de ponto ou função de estado, são as propriedades que definem a situação de um sistema (estado) em um determinado instante. Sua representação em um diagrama qualquer é de um ponto, em que dois pontos distintos da curva representam duas características intrínsecas do sistema, e o conjunto infinito de pontos que compõe a curva é a descrição completa do que ocorreu com o sistema ao longo de um processo. 

PRINCIPAIS CONCEITOS EM LIVROS DIDÁTICOS

De modo que como o próprio nome já nos diz, essas propriedades dependem apenas do estado e não da forma como um dado sistema chegou nesse estado. Essas funções possuem diferenciais exatas as quais são representadas pela letra (d).

Definição 4: Uma variável de estado é toda e qualquer grandeza física que pode ser usada para descrever ou quantificar as características de um sistema termodinâmico durante um processo.

Com isso, poderíamos citar como exemplos a temperatura $(\mathrm{T})$, a pressão $(\mathrm{P})$, o volume (V), a quantidade de matéria (N), dentre outras. Em Termodinâmica é comum o uso de funções de uma ou mais variáveis, e atribuímos a essas variáveis alguma dessas grandezas.

Com base nessas definições poderíamos dizer que uma variação infinitesimal no volume de um sistema seria representada por $d V$, enquanto que uma quantidade infinitesimal de calor ou de trabalho é representada por $\delta Q$ ou $\delta W$ respectivamente. Muitas vezes é comum haver dúvidas, ou mesmo possível confundir o que são acréscimos e diferenciais exatas e inexatas, com seus usos diversos em variados contextos da Termodinâmica.

Usualmente atribuímos ao símbolo $\Delta x$ ou $\Delta y$ a uma variação ou diferença finita entre dois valores da grandeza x e y, e por representar uma diferença, o símbolo $\Delta$ tem o significado de um incremento, acréscimo, intervalo, etc. Em que:

$$
\begin{aligned}
& \Delta x=x_{2}-x_{1} \\
& \Delta y=y_{2}-y_{1}
\end{aligned}
$$

Em que o significado do símbolo $\Delta$ é justamente uma diferença ou variação entre valores de uma grandeza. Seu uso é amplamente evidente em vários campos de estudo da Física. Uma característica dessa representação simbólica é que este símbolo só deve estar associado a grandezas que sejam funções de ponto; não tem significado sua aplicação a grandezas que tenham comportamento de funções de linha, a não ser em casos particulares, uma vez que a diferença representada na equação (3), significa o valor da grandeza x no estado final 2 menos o valor de x no estado inicial 1, é análogo à y.

Em alguns casos particulares, como mencionado, uma função de linha assume características de função de ponto e, nessas condições, ela pode (mas não deve) ser representada por uma diferença; contudo, deve-se ter sempre em mente que se trata de um caso particular e não geral. É com base nessa discussão que vamos entrar em uma das questões centrais dessa 
seção, a saber; o entendimento da formulação matemática do Primeiro Princípio da Termodinâmica.

Já vimos em outros tópicos que:

$$
\Delta U=Q-W
$$

Onde: $\Delta U \equiv U_{\text {final }}-U_{\text {inicial }}$, que é a variação de energia interna do sistema devido à transformação; (Q) é o calor acrescido ao sistema durante a transformação e (W) é o trabalho realizado pelo sistema durante essa transformação. Voltamos a enfatizar que é evidente a partir dessa formulação que a Primeira Lei da Termodinâmica define o que é a variação da energia interna e assim não podemos deduzir o que seria a energia interna somente a partir dessa expressão, daí pode-se ver a importância das definições associadas às leis.

Sabemos pela definição que (U), a energia interna do sistema é uma propriedade/função termodinâmica de estado (função de ponto), enquanto que (Q) e (W), respectivamente, o calor e o trabalho são propriedades/funções de transformação (função de linha). Desse modo, o que vemos aqui é que a lei expressa por meio dessa equação (3) está relacionando duas grandezas ditas de transformação a uma de estado usando o operador $\Delta$. E como foi dito acima, não existe sentido em usar esse operador em grandezas com comportamento de funções de linha, mas talvez a grande exceção a isso seja justamente essa definição da Primeira Lei.

Para o caso de transformações adiabáticas, em que não há trocas de calor, tem-se:

$$
\Delta U=-W
$$

Nesta situação o trabalho irá se comportar de forma diferente do que diz a definição de função de linha, isso porque neste caso o trabalho assume características de uma função de ponto, ou seja, $W=U_{\text {inicial }}-U_{\text {final }}$ e o mesmo pode ser dito do calor para o caso de uma transformação isovolumétrica, onde nenhum trabalho é realizado, ele também assumiria características de função de ponto. Mas mesmo o trabalho e o calor estando nessas condições ainda podemos dizer que eles ainda mantêm as suas características de função de transformação (em seu sentido físico pelo menos) e não podendo assim ser classificadas como propriedades termodinâmicas de estado.

Agora, quando se faz o uso das representações diferenciais $d x$ ou $d y$ queremos dizer que são diferenças infinitesimais. Fisicamente essas diferenças podem ser interpretadas como diferenças que "não podem ser medidas" e, mesmo sendo isso meio contraditório, essa ideia, é 


\section{PRINCIPAIS CONCEITOS EM LIVROS DIDÁTICOS}

da maior utilidade matemática-conceitual em quase todos os estudos que se faça nas ciências exatas e naturais.

Um resultado importante que sabemos do cálculo é que a diferenciação (derivação, a grosso modo) só ocorre em funções contínuas em um dado intervalo $[a, b]$ e como as funções contínuas podem ser classificadas em funções de ponto ou funções de linha, a operação diferencial aplicada a cada tipo de função conduz a resultados diferentes; devido a esse fato, as diferenciais podem ser classificadas em: i) diferencial total ou exata e ii) diferencial inexata.

E já definimos as devidas notações para cada tipo dessas diferenciais, e agora consideremos como válidas as expressões seguintes:

$$
\begin{aligned}
& \int d U=U \\
& \int \delta Q=Q \\
& \int \delta W=W
\end{aligned}
$$

Assim, para uma transformação termodinâmica infinitesimal, o Primeiro Princípio da Termodinâmica pode ser reduzido a expressão:

$$
d U=\delta Q-\delta W
$$

Essa é uma redução natural do caso macroscópico ou dito em outras palavras, do caso, mensurável para o infinitesimal (não mensurável), e ao escrevermos essa expressão dessa forma não perdemos em nada em termos de simplicidade, mas quando essa expressão for escrita na forma:

$$
d U=d Q-d W
$$

Nessa expressão, temos as diferenciais tidas como exatas $d Q$ e $d W$, contudo, isso não é válido de acordo com as definições estabelecidas anteriormente.

\subsection{Segunda Lei e Entropia}

Já discutimos algumas ideias e conceitos relevantes para que possamos vir a entender o mínimo necessário do significado da Segunda Lei da Termodinâmica, e agora vamos novamente introduzir uma nova função de estado a qual já a mencionamos teoricamente e sabemos que ela está intimamente relacionada com o enunciado da Segunda Lei, ou seja, essa função a qual nos referimos é a entropia. Logo, faz-se necessário a seguinte definição: 
Definição 5: Se um sistema Termodinâmico à temperatura (T) troca calor $\delta Q$ com sua vizinhança em um processo infinitesimal qualquer admitido como reversível, sua variação de entropia $d S$ é dada pela relação:

$$
d S=\frac{\delta Q}{T}
$$

Por questões de clareza notacional, vamos denotar o calor trocado reversivelmente (aquele que ocorre somente em processos reversíveis) por $d Q_{r e v}$, de modo que a equação (9) fica:

$$
d S=\frac{d Q_{r e v}}{T}
$$

Sabe-se que a entropia de um sistema é uma propriedade extensiva, e isso tem implicações importantes para certos resultados obtidos na teoria. Esta grandeza foi descoberta e definida pela primeira vez por Rudolph Clausius em meados de 1865 e também foi ele que cunhou o termo entropia.

Duas expressões também muito importantes relacionadas a entropia que são denominadas de Princípio de Aumento da Entropia e de Nulidade da Entropia são dadas respectivamente por:

$$
\begin{gathered}
d S \geq \frac{\delta Q}{T} \\
d S \geq 0
\end{gathered}
$$

Dessas expressões, nos atentando para o que ocorre com a entropia, tem-se: caso tenhamos um processo irreversível o grau de entropia terá um aumento crescente; se o processo for reversível, a variação de entropia será nula; e vale ressaltar que ainda sobraria uma possibilidade, que seria a diminuição da entropia, porém isso implicaria em processos “impossíveis". Em resumo, podemos dizer que só existem duas possibilidades que é o aumento ou a nulidade da entropia nos processos termodinâmicos possíveis.

Com menção ao Princípio de Aumento da Entropia, é conveniente dizer que é com base nessas ideias que chegamos a um dos pontos culminantes da teoria da Termodinâmica Clássica, e esse argumento é firme o suficiente para justificar o porquê que as máquinas térmicas não podem operar infinitamente através de um dispositivo ideal, o chamado motor contínuo. Embora deve-se ter em mente que o uso de máquinas térmicas executando ciclos (reversíveis ou irreversíveis) e gerando trabalho talvez, não seja, a maior das generalizações para os estudos Revista RBBA $\mid$ Revista Binacional Brasil Argentina 
mais gerais da Termodinâmica, por assim dizer; "as máquinas térmicas são instrumentos idealizados que abrem grandes possibilidades para uma generalização suficientemente ampla sobre a conversão de energia fornecida na forma de calor em trabalho mecânico útil”" (BRAGA, 1998, apud OLIVEIRA et all., 2017, p. 3).

De acordo o enunciado da Segunda Lei, todo processo que ocorre em um sistema isolado tende a um aumento crescente de entropia, e esse tende a um valor máximo, que depois de atingido diz-se que o sistema chegou a seu estado de equilíbrio, o qual não mais permite qualquer mudança no sistema, de tal modo a implicar na redução do grau de entropia.

\subsection{Terceira Lei e Temperatura}

Vimos a partir da Segunda Lei da Termodinâmica a importância que o conceito de entropia ganhou, e, realmente essa ideia de entropia é de grande utilidade em toda a Termodinâmica Clássica e também na Mecânica Estatística. Nessa discussão sobre a terceira lei vamos incluir certos aspectos envolvendo as ideias de temperatura e estender sutilmente as concepções da Segunda Lei para chegar em alguns novos resultados.

Pode-se iniciar essa discussão de forma bem simples, relembrando daquela noção de temperatura que apresentamos anteriormente. Nela dissemos que essa grandeza está intimamente relacionada com o grau de "agitação das moléculas" do sistema, ou seja, quanto maior a temperatura, maior é também a energia cinética média das moléculas constituintes de um sistema. Claro que essa é apenas uma noção básica e essa associação entre temperatura e agitação térmica é limitada em certos pontos, porém, vamos usá-la para darmos início a nossa discussão.

Neste contexto, devemos lembrar também que existe uma relação entre a temperatura e a entropia, o que sabemos é que a entropia mede o nível de desordem molecular de um sistema, e é bastante intuitivo o fato de que se aumentarmos a temperatura em um sistema aumenta-se consequentemente a movimentação molecular, o que implica uma maior entropia.

A entropia como já sabemos é uma função de estado, e assim, existem certas variáveis que corroboram para descreve-la, consideremos como principais o volume (V), a energia interna $(\mathrm{U})$ ou o número de partícula $(\mathrm{N})$, e desse modo, podemos definir a entropia como uma função da forma $S=S(U, V, N)$, mas para uma simples análise dos conceitos fixados, consideramos que o volume $(\mathrm{V})$ e o número de partículas $(\mathrm{N})$ como constantes, de forma que a 

PRINCIPAIS CONCEITOS EM LIVROS DIDÁTICOS

função fica $S=S(U)$, isso porque geralmente a energia interna (U) não é fixa durante um processo. Assim, a definição termodinâmica de temperatura (T) pode ser dada por:

$$
T=\frac{\Delta U}{\Delta S}
$$

Já o Segundo Princípio da Termodinâmica, o conceito de entropia se tornou preponderante. Nessa nova etapa dos desenvolvimentos termodinâmicos a temperatura rivaliza em termos de importância com a entropia. Essa equação (12) apresentada é uma maneira mais teórica de se obter a temperatura de um sistema, em comparação com a forma experimental proposta pela ideia do equilíbrio térmico da Lei Zero.

De certa forma, buscamos agora encontrar alguns limites para a Termodinâmica e é justamente isso que de alguma forma a Terceira Lei faz. Até hoje, pelo que sabemos não foi possível se fazer de forma experimental qualquer sistema termodinâmico chegar a uma temperatura que seja menor ou igual ao zero absoluto $(\mathrm{T}=0)$ apesar de se chegar bem próximo a ela. Essas e outras indagações nos levam a considerar apenas sistemas em que $T \rightarrow 0$ e desconsiderar a possibilidade da existência de sistemas com $(\mathrm{T}=0)$.

\section{CONCLUSÃO}

Conforme foi apresentado no corpo desse artigo, as Leis da Termodinâmica, de modo geral, podem ser apresentadas de mais de uma forma. Todavia, da análise do silogismo aristotélico, percebemos que a maioria das fontes pesquisadas não partiu de elementos fundamentais precisos para apresentar uma definição consistente.

Isso ocorreu, pois, nessas fontes, termos como "Energia Interna", "Calor", "Trabalho", "Temperatura", "Entropia”, dentre outros, não foram bem definidos. Dessa forma, mesmo que tenham apresentado textos interessantes, por não partirem de uma premissa valida, não são corretos.

Por isso, entendemos que se fez necessária a apresentação de nossas próprias definições de muitas dessas grandezas, e também, de expor a nossa própria interpretação das Leis da Termodinâmica. Tanto essas definições, quanto a nossa interpretação das leis, foram apresentadas entre as seções três e seis desse artigo.

Além da definição pouco precisa dessas grandezas, consideramos que os textos analisados possuem uma abordagem matemática insuficiente para a compreensão do discente. 
Logo, como entendemos que a apresentação das relações matemáticas que envolvem as leis, juntamente com uma análise das mesmas, são de suma importância para o real entendimento do conteúdo abordado, fizemos, na seção sete, uma abordagem sobre essas equações. Então, não só apresentamos elas, mas, justificamos a sua importância ao relaciona-las com as definições das leis.

Todo esse cuidado é imprescindível, pois, conforme apresentamos, a Termodinâmica é um dos ramos mais antigos da Física e com maior importância prática no nosso cotidiano. Todavia, talvez, justamente por isso, possui definições tão divergentes quando fazemos uma análise em fontes diversas. Pois, como são grandezas ligadas ao cotidiano, nem sempre é tomado o devido cuidado para separar o senso comum do conhecimento cientifico. Além disso, por ser um ramo antigo, muitos dos termos utilizados em alguns trabalho e replicados por outros, já caíram em desuso. Dessa forma, se fazem necessários trabalhos que busquem definir de forma correta as grandezas termodinâmicas, para assim elucidar os estudantes de qual é o real significado delas.

\section{REFERÊNCIAS}

ARISTÓTELES. Segundos Analíticos: Livro I. Tradução, introdução e notas de Lucas Angioni. Campinas: IFCH/UNICAMP - Setor de Publicações, fevereiro de 2004. (Clássicos da Filosofia: Caderno de Tradução no 7 ).

ÇENGEL, Yunus A. BOLES, Michael A. Termodinâmica. 5ª Ed. Mcgraw Hill, 2007.

CORREIA, J. J. Definições de temperatura em fontes didáticas. Revista Binacional BrasilArgentina: Diálogo entre as ciências, [S.1.], v. 6, n. 1, p. 201-220, out. 2017. ISSN 2316-1205. Disponível em: http://periodicos2.uesb.br/index.php/rbba/article/view/1520. Acesso em: 03 de janeiro de 2019. Disponível em: https://doi.org/10.22481/rbba.v6i1.1520.

CORREIA, J. J; GUIMARÃES, G. F. Definição da energia livre de Helmholtz em fontes didáticas. Revista Binacional Brasil-Argentina: Diálogo entre as ciências, [S.1.], v. 8, n. 2, p. 127-155, mar. 2020. ISSN 2316-1205. Disponível em: <http://periodicos2.uesb.br/index.php/rbba/article/view/5784>. Acesso em: 08 ago. 2020. doi: https://doi.org/10.22481/rbba.v8i2.5784.

CORREIA, J.J.; MAGALHÃES, L. D. R. Obstáculos Epistemológicos na transposição didática do Calor. In: IX CÓLÓQUIO DO MUSEU PEDAGÓGICO. (ISSN 2175-5493), Vitória da Conquista (BA), Anais. Vitória da Conquista. MUSEU PEDAGÓGICO CASA PADRE PALMEIRA. 2009. v. 8, n. 1. p. 727-740, 2009. Disponível em: http://periodicos.uesb.br/index.php/cmp/article/viewFile/3574/3265. Acesso em: $10 \mathrm{de}$ novembro de 2019. 
CORREIA, J. J; JOSÉ, W. D. O conceito de trabalho de uma força em livros didáticos, In: IX COLÓQUIO DO MUSEU PEDAGÓGICO (ISSN 2175-5493), Vitória da Conquista (BA), Anais. Vitória da Conquista. MUSEU PEDAGÓGICO CASA PADRE PALMEIRA. 2011. v. 9, n. 1, p. 727-740, 2011. Disponível em:

http://periodicos.uesb.br/index.php/cmp/article/viewFile/2663/2330. Acesso em: $10 \mathrm{de}$ novembro de 2019.

COSTA, E. C. Física Industrial - Enciclopédia Técnica Universal. Tomo I, termodinâmica, I Parte. Porto Alegre: Globo, 1971.

LEITE, Maria; ALMEIDA, Maria. Compreensão de Termos Científicos no Discurso da Ciência. Rev. Bras. Ensino Fís. São Paulo, v. 23, n. 4, p. 458-470, Dec. 2001. Disponível em: <http://www.scielo.br/scielo.php?script=sci_arttext\&pid=S1806-11172001000400011 $\& \operatorname{lng}=$ en\&nrm=iso>. Acesso em: 12 nov. 2020.

MÁXIMO, A.; ALVARENGA B. Curso de Física, volume 2. $1^{\text {a }}$ Edição. São Paulo. Editora Scipione: 2011.

NAKAZA, R. M.; LINHARES, O. B. "O silogismo científico em Aristóteles" Jornada de Iniciação Científica e Mostra de Iniciação Tecnológica - ISSN 2526-4699 (2007). Disponível em https://philarchive.org/archive/NAKOSC. Acesso em 25 jun. 2020.

OLIVEIRA, P. H. F.; LIMA, W. P.; PIRES, A. I. P.; SENA, S. H. R. Demonstração da Desigualdade de Clausius Pelo Teorema do Máximo Trabalho. UNILAB: ANAIS DA SEMANA UNIVERSITÁRIA, Ceará-Bahia, 2017.

TIPLER, Paul A. Física 1. Rio de Janeiro. LTC. 1976.

\section{Notas}

\footnotetext{
${ }^{\text {i }}$ Disponível em <http://sisne.org/Disciplinas/Grad/Fisica2FisMed/aula23.pdf>. Acesso em: 11 set. 2020.

ii Disponível em <http://sisne.org/Disciplinas/Grad/Fisica2FisMed/aula23.pdf>. Acesso em: 11 set. 2020.

iii Disponível em <https://pt.wikipedia.org/wiki/Nicolas_L\%C3\%A9onard_Sadi_Carnot>. Acesso em: 11 set. 2020.
} 